\title{
O processo de federalização da ESEF/UFRGS sob a perspectiva dos professores o estudo de um caso
}

Cássio Felipe Tejada Nunes ${ }^{*}$ Vicente Molina Neto

\begin{abstract}
Resumo: Esta investigação é um estudo de caso que busca compreender o processo de incorporação da Escola de Educação Física à Universidade Federal do Rio Grande do Sul, ocorrido em 1969, na perspectiva dos professores. O processo analítico procura relacionar o contexto sociopolítico da época com a história de vida de um Professor atuante nessa época.
\end{abstract}

Em 1969, a Escola Superior de Educação Física (ESEF), então vinculada à administração do estado do Rio Grande do Sul, passou a integrar a Universidade Federal do Rio Grande do Sul. Esse processo ficou conhecido pela expressão "Federalização da Escola".

Para melhor compreender a Federalização realizamos um estudo preliminar sobre o tema (Nunes et all., 2000). Neste estudo, buscamos compreender este processo sob a perspectiva dos alunos formandos em 1968, 1969 e 1970, identificando as principais características e conseqüências deste processo para esses formandos. Das 13 entrevistas realizadas, uma delas atevese a obter esclarecimentos com um Professor que foi membro do Conselho Universitário da UFRGS na época, a qual trouxe importantes informações sobre o modo com que a incorporação da ESEF pela UFRGS foi abordada nesse Conselho. As entrevistas com os estudantes foram vitais para a realização da pesquisa tendo em vista a escassez de documentos sobre o tema, embora eles pouco pudessem acrescentar sobre o enfoque político-administrativo do processo.

Alguns estudantes se consideraram desinformados naquele período. Em conseqüência, acabaram à parte dos acontecimentos. A maioria dos colaboradores afirmou desconhecer as Reformas Universitárias de 1968, que tiveram grande repercussão no

* Professor de Educação Física, apoio FAPERGS.

** Professor de Graduação e Pós-Graduação da ESEF/UFRGS, apoio CNPq.

1 Termo utilizado por antigos professores e funcionários.

Movimento, Porto Alegre, v. 11, n. 2, p.167-190, maio/agosto de 2005 
futuro da Universidade brasileira. Outros estudantes sublinharam seu vínculo com a política estudantil no diretório acadêmico da Escola e sua relação como o Diretório Central dos Estudantes. Porém, mesmo os estudantes "politicamente ativos" ressaltaram a dificuldade de obter informação sobre o enfoque político e administrativo desse processo.

Segundo os estudantes, no contexto histórico da Federalização a repressão imposta pelo Governo Militar era intensa, ${ }^{2}$ e era raro o acesso aos assuntos de natureza político-administrativa. Afirmaram que embora os professores não fizessem referências formais sobre o assunto, acreditavam que estes, de modo provável, sabiam mais sobre o processo do que eles, pois, a incorporação da ESEF à UFRGS, demandaria alterações em seu cotidiano profissional. Ao término da pesquisa, compreendemos que o processo de Federalização possibilitou alterações na estrutura da Escola, além de trazer para os estudantes que ali se formam uma sensível melhora no status, na valorização e no reconhecimento do profissional de Educação Física formado por essa instituição.

Mas, em relação ao professores, que alterações o processo de Federalização pode ter gerado em suas vidas? Será que os professores também estavam à parte dos acontecimentos ou apenas não comentavam o assunto por outras razões?

Essa questão direcionou nosso foco de atenção para a segunda pesquisa (Nunes e Molina Neto, 2002), na qual buscamos ampliar a compreensão desse processo. Nosso objetivo constituiu-se em compreender a Federalização sob a perspectiva dos professores e identificar os efeitos desse processo em suas vidas. Dada a natureza do processo e a dificuldade de estabelecer a representatividade dos colaboradores, optamos por um estudo de caso.

\section{O contexto histórico da época}

Na história recente do Brasil, a década de sessenta do século XX provavelmente tenha sido a mais efervescente quando analisamos o contexto mundial sob os aspectos sociais, econômicos, políticos e culturais. Nesse período, os países comunistas e os capitalistas, encabeçados pela União Soviética e

2 Em 1969 é editado o Ato Institucional n. ${ }^{\circ} 5$, instrumento legal que simboliza a cassação dos direitos individuais pelo governo militar da época.

Movimento, Porto Alegre, v. 11, n. 2, p.167-190, maio/agosto de 2005 
pelo Estados Unidos da América respectivamente, buscaram incessantemente impor a sua supremacia política e econômica sobre as demais nações. Segundo os jornais da época, ao longo dessa década tivemos a construção do Muro de Berlim (1961), a crise dos mísseis em Cuba (1962) e a Revolução Cultural de Maio de 1968 na França como exemplos de acontecimentos que entraram para a história mundial, pois influenciariam as atitudes e modos de vida das pessoas em vários pontos do Planeta.

Centrando-nos em nosso país, temos um quadro econômico entre 1930 e 1964 que pode ser caracterizado por um equilíbrio mais ou menos estável entre o modelo político de tendências populistas e o modelo de expansão de indústrias, principalmente indústrias de base. O Estado teve fundamental participação na implantação das condições mínimas para o desenvolvimento industrial e, assim, recebeu apoio do empresariado que, por sua vez, "tolerou o nacionalismo, como ideologia do governo, em determinadas épocas" (ROMANELLI, 1978, p. 193). Contudo, o aumento progressivo de capital internacional rompeu o equilíbrio existente entre o Estado e o empresariado brasileiro, causando um "afastamento" entre o modelo político e econômico vigente no país.

No governo de João Goulart foi preciso, para manter o alto Produto Interno Bruto (PIB), reduzir progressivamente a pressão inflacionária e as desigualdades econômicas e sociais regionais, além de superar o subdesenvolvimento do país. Para tanto, foi realizada uma série de reformas: a tributária, a bancária, a administrativa e, principalmente, a agrária (XAVIER,1994). Contudo, pressões de diferentes setores sociais inviabilizaram o plano do governo. No final de março de 1964, o governo de João Goulart estava “espremido entre a mobilização golpista que reunia maior parte da cúpula militar unida aos setores mais conservadores da sociedade e entre o crescente movimento popular que exigia a implantação de reformas estruturais" (BARROS, 1994, p.17). Assim, com o apoio maciço das elites nacionais e forte apoio estrangeiro, de modo especial dos Estados Unidos da América, prevaleceu a força conservadora e ocorreu o Golpe Militar de 1964 (BARROS, 1994).

Movimento, Porto Alegre, v. 11, n. 2, p.167-190, maio/agosto de 2005 


\section{A educação na década de 1960}

Na primeira metade dos anos 1960 a educação estava em dissonância com a economia. O sistema de ensino cresceu em quantidade, mas não em qualidade, o que é compreensível, pois, "o sistema político não permite às escolas a função de alargar os horizontes do saber crítico de quem delas se alimentava" (DAMASCENO, 1978, p.87). Em decorrência disso, diferentes segmentos sociais reivindicavam melhorias no ensino.

A partir de 1964, o sistema de ensino brasileiro passou por uma série transformações. O objetivo estabelecido para a escola foi formar mão-de-obra para suprir o processo de industrialização em andamento. Para isso, o governo utilizou uma série de decretos, inspirados em políticas educacionais que tiveram a interferência do capital estrangeiro.

\section{A Lei de Diretrizes e Bases da Educação Nacional (LDBEN)}

A Lei das Diretrizes e Bases (Lei ${ }^{\circ}$ 4.024/61) "objetivava dar maiores contornos liberais e democráticos ao sistema de ensino brasileiro, porém, na obra final, se salientava o caráter puramente ideológico..." (TAMIOSSO E MAZO, 1991, p.49). A Lei acabou sendo uma repetição de outras tentativas desesperadas para solucionar com urgência os problemas gerados pelo distanciamento entre o sistema escolar e as necessidades de desenvolvimento.

Cabe, aqui, uma ressalva: em seu artigo 22, a Lei $\mathrm{n}^{\circ} 4.024$ / 61 traz ratificada a obrigatoriedade da Educação Física nos níveis primário e médio, embora ainda não fosse obrigatória no nível superior, de acordo com Castellani Filho (1988).

\section{Os acordos MEC (Brasil) e USAID (Estados Unidos)}

A partir da década de 1950, o Brasil passou a firmar com os Estados Unidos acordos de intercâmbio de conhecimento, através do Ministério da Educação e Cultura (MEC) e a USAID (United States Agency for International Development), com a justificativa de fazer com que a educação acompanhasse o ritmo de desenvolvimento econômico do país. Entre as principais ações dos conhecidos "Acordos MEC-USAID", destaca-se o livro $R u$ -

Movimento, Porto Alegre, v. 11, n. 2, p.167-190, maio/agosto de 2005 
mos à Reformulação Estrutural da Universidade Brasileira, de Rudolph Atcon, em 1966. O "Plano Atcon", como ficou conhecido, foi a base da influência estrangeira na Reformulação Estrutural da Universidade Brasileira, publicado pelo MEC em 1966, que em dois anos resultaria na Reforma Universitária.

Evidentemente, havia manifestações contrárias a essa série de acordos, predominantemente de segmentos estudantis, o que agravou, na época, a situação da crise educacional. A UNE, embora na clandestinidade até 1968, protestava com força contra os Acordos MEC-USAID. Contudo, o governo, através da Comissão Meira Matos e outros órgãos de controle e repressão como o DOPS e o DOI-CODI, fez com que não só a UNE, mas todo o movimento estudantil desmoronasse totalmente em 1968 (TAMIOSSO e MAZO,1991). Assim, o governo pode implementar o seu projeto da Reforma Universitária, principalmente pela entrada em vigor do Decreto-lei $\mathrm{n}^{\circ} 477$, que permitiria reprimir com rigor a crítica e as manifestações políticas no interior de escolas e universidades (XAVIER, 1994).

\section{A Reforma Universitária}

A Reforma Universitária começou com um projeto de lei elaborado por um grupo de onze membros, designados pelo então presidente Costa e Silva, em julho de 1968, pelo decreto $\mathrm{n}^{\circ}$ 62.937, de 1968, e atendeu às orientações da USAID, visando a eficiência, a modernização, a flexibilidade administrativa e a formação de recursos humanos de alto nível para o desenvolvimento da nação. O projeto da Reforma foi encaminhado ao Congresso Nacional diretamente pelo presidente, foi aprovado em regime de urgência, em torno de 40 dias. LAMPERT (1995) comenta que no período pós-golpe até 1968, as questões pertinentes ao ensino superior sempre haviam sido tratadas tecnicamente. Contudo, a aprovação da Lei 5540/68, Lei da Reforma Universitária, foi um ato político autoritário.

Entre as inovações dessa Reforma, estavam os exames vestibulares classificatórios, a instituição do sistema de créditos e matrícula por disciplina, a organização semestral, flexibilidade na organização curricular, extinção da cátedra (substituída pelo sistema departamental), reestruturação administrativa, perda de autonomia e controle externo das Faculdades, instituição de programas de pós-graduação (Mestrado e Doutorado), e outros, e ainda tinha o caráter implícito de manter sob controle as

Movimento, Porto Alegre, v. 11, n. 2, p.167-190, maio/agosto de 2005 
atividades políticas dos estudantes, contestadores do governo que deveriam ser controlados para a manutenção do regime que vigorava desde 1964.

Quando realizamos a pesquisa com os estudantes do período em que as Universidades estavam sob a égide da Reforma de 1968, um dos entrevistados comentou que antes da "departamentalização" das Faculdades as turmas eram mais unidas e mobilizáveis para diversos fins. Segundo ele "havia uma integração muito grande entre os estudantes. A reforma universitária veio com o intuito de pulverizar essa... essa força que os estudantes tinham, e o que foi, de certa forma, conseguido" (NUNES et al., 2000, p.19). O rompimento das unidades de turma, decorrentes da inclusão do sistema departamental e de créditos, contribuiu para a desmobilização das organizações estudantis.

\section{A valorização da Educação Física para promover a alienação política}

Com a Lei das Diretrizes e Bases de 1961 já tinha sido ratificada a obrigatoriedade da Educação Física nos níveis de ensino Primário e Médio. Entretanto, após a Reforma Universitária de 1968, através do Decreto-lei $\mathrm{n}^{\circ}$ 705, de 25 de Julho de 1969, a disciplina Educação Física passou a ser obrigatória também no ensino superior, que entre outras coisas, visava "colaborar, através de seu caráter lúdico-esportivo, com o esvaziamento de qualquer tentativa de rearticulação política do movimento estudantil" (CASTELLANI FILHO, 1988, p.121).

Nesse sentido, os jogos acadêmicos, universitários e ou outros do gênero foram instrumentalizados com o objetivo de redirecionar o tempo e a energia dos estudantes que se destinavam às manifestações contra o Governo para a prática desportiva. Os exemplos mais visíveis foram os Jogos Escolares Brasileiros (JEBs) e os Jogos Universitários Brasileiros (JUBs).

Interessava ao governo o incentivo à prática de esportes, ligados à prática de Educação Física Escolar, cujo objetivo era a formação integral do homem. Esse interesse implicou a necessidade de ampliar o número de professores de educação física, criar novos institutos de formação inicial e a "Federalização" das Escolas de Educação Física existentes". Daí, uma das características que justificavam essa disciplina no sistema educacional: sua ênfase mais legalista do que pedagógica.

Movimento, Porto Alegre, v. 11, n. 2, p.167-190, maio/agosto de 2005 


\section{A incorporação da ESEF de Porto Alegre à UFRGS}

Foi determinado às universidades brasileiras pelo Conselho Federal de Educação (CEF) que realizassem reformulações em sua estrutura, para se adaptarem às inovações da Reforma Universitária de 1968, previstas nos Decretos-Lei no 53 de 1966 e no no 252 de 1967.

Observando as atas das reuniões do Conselho Universitário (CONSUN) da UFRGS (Universidade Federal do Rio Grande do Sul) ocorridas entre 1966 e 1968, constatamos freqüentes discussões sobre a reforma do estatuto da universidade e sobre a possibilidade da Escola de Educação Física ser incorporada a UFRGS. A Escola Superior de Educação Física, criada em 1940, era administrada pela Secretaria Estadual de Educação do estado do Rio Grande do Sul.

De modo específico, na reunião ocorrida em 22 de fevereiro de 1968, houve a manifestação de um pequeno grupo de professores liderados pelo então representante dos professores adjuntos, Professor Jorge Honório M. Brito, que defendia a hipótese da ESEF ser federalizada na reforma do estatuto. Ele acreditava em tal possibilidade, pois não havia normas que impedissem a sua incorporação, pois, a ESEF era um estabelecimento de ensino superior e isso não constituiria a criação de uma nova Faculdade, o que era vetado pelo CFE. Porém, a proposição do Professor Brito foi votada e seus argumentos não conseguiram convencer o Conselho a federalizar a ESEF. Em entrevista com o Professor Brito, ele declarou acreditar que uma das questões pelas quais sua hipótese foi vetada é que os professores que atuavam na ESEF naquele momento seriam os professores fundadores das respectivas cátedras na época, no caso de incorporação, e isso não era bem visto pelos membros do CONSUN principalmente porque tal situação "colocaria estes professores numa condição de estabilidade sem concurso, porque na época que a escola era estadual não existia o critério de concurso público para o ingresso no magistério [estadual]".

O ocorrido no CONSUN da UFRGS não foi um fato isolado. Segundo SOUZA (1995), no CONSUN da Universidade Federal de Minas Gerais (UFMG) também ocorreram discussões para

3 Fragmento do relato do Prof. Jorge Honório M. Brito, em entrevista realizada para a pesquisa "O Processo de Federalização da Escola de Educação Física: A visão dos alunos formandos em 1968, 1969 e 1970"

Movimento, Porto Alegre, v. 11, n. 2, p.167-190, maio/agosto de 2005 
que a Escola de Educação Física, situada em Belo Horizonte, fosse incorporada à Universidade Federal local. Porém, segundo a autora, o CONSUN da UFMG manifestou-se a favor da incorporação a partir de 1968. Entretanto, sabe-se que nem a ESEF de Porto Alegre nem a Escola de Educação Física de Minas Gerais (EEFMG) foram federalizadas através dos respectivos CONSUN's de suas respectivas universidades locais.

De acordo com SOUZA (1995), com a política de incentivo à prática de atividades físicas, paralelamente exigiu-se um aumento do número de profissionais qualificados para levar adiante essa prática. Segundo a autora, para suprir essa demanda necessária de professores de Educação Física, a Junta Militar que governava o país naquele momento incorporou a EEFMG através Decreto-Lei no 997 de 21 de novembro de 1969. Entretanto, a EEFMG não foi a única "contemplada", pois o mesmo decreto integrou a Escola de Serviço Social de Natal à Universidade Federal de Natal, e a ESEF de Porto Alegre à UFRGS.

Essa incorporação da ESEF é compreensível dentro de toda essa política de incentivo ao esporte e à atividade física. Podemos observar que apesar da educação estar sempre em voga nos Decretos e reformas, havia escassez de verbas para o ensino público. Contudo, o Departamento de Educação Física e Desportos do MEC garantiu "volumosos recursos que permitiram reaparelhar e construir uma nova sede para a Escola de Educação Física da UFMG, o que não deixava sombra de dúvidas sobre o interesse do governo pela Educação Física e pelos esportes" (SOUZA, 1995, p.32). Acreditamos que com a ESEF/UFRGS não foi diferente, tendo em vista alterações na estrutura física da escola poucos anos após o ato de Federalização.

\section{Decisões metodológicas}

A presente pesquisa contém um viés qualitativo, de modo específico um estudo de caso orientado por uma "História de Vida" (TRIVIÑOS,1987). Em estudo que realizamos, envolvendo a Federalização da ESEF surgiram algumas dúvidas sobre a participação dos professores da Escola nesse processo e também como ele repercutiu em suas vidas. Julgamos que o Estudo de um Caso envolvendo o corpo docente poderia esclarecer tais questões e aprofundar o conhecimento sobre a Federalização, pois, esse tipo de procedimento utiliza a perspectiva dos sujeitos que vivenciaram o fato histórico.

Movimento, Porto Alegre, v. 11, n. 2, p.167-190, maio/agosto de 2005 
O primeiro passo da pesquisa, após a delimitação do problema e dos objetivos, foi a procura de um Professor que atuasse na ESEF/UFRGS no período entre 1968 e 1970 para a realização do Estudo de Caso. Optamos pelo Professor Fredolino Taube pois, tendo sido diretor da ESEF, no ano de 1970, vivenciou a expectativa e a concretização do processo de Federalização. Somase a isto o fato de ter sido um profissional com experiência docente em todos os níveis de ensino e de reconhecida conduta moral e ética, tanto por parte de ex-funcionários quanto por exalunos.

A etapa seguinte da pesquisa caracterizou-se pelo estudo de nossas fontes, ou seja, uma revisão de documentos da época do processo (Jornais, Decretos, Decretos-Lei) e de referências bibliográficas sobre História do Brasil e História da Educação. Na seqüência, dividimos o estudo em duas fases: A pesquisa de campo ou coleta de informações e a análise destas informações.

Foram realizadas duas entrevistas com Fredolino Taube. Na primeira delas privilegiamos os aspectos relacionados com sua história de vida, enquanto que na segunda priorizamos questões referentes a sua trajetória na ESEF, mais especificamente na Direção da Escola e o seu envolvimento com o processo de Federalização.

Além das entrevistas com Fredolino Taube entrevistamos dois de seus ex-alunos que, atualmente, são professores da ESEF/ UFRGS, um dos quais foi seu monitor. Tivemos a oportunidade de entrevistar, ainda, uma funcionária aposentada do serviço público que trabalhou sob sua orientação e por 25 anos na ESEF. Segundo Triviños (1987), essas entrevistas fazem-se necessárias para uma concepção mais fiel da História de Vida.

Salientamos que todas as entrevistas realizadas foram gravadas e transcritas para a análise das informações na fase seguinte da pesquisa. As transcrições das entrevistas foram revisadas pelos colaboradores que atestaram sua validez e autorizaram o uso do material transcrito.

As entrevistas foram revisadas e os relatos, de acordo com os seus teores, originaram as unidades de significado. Estas, por sua vez, foram reunidas de acordo com a sua afinidade, originando as categorias de análise deste estudo. Essa etapa conhecida como categorização, juntamente com os achados na fase de revisão bibliográfica, forneceram os subsídios para as considerações apresentadas a seguir.

Movimento, Porto Alegre, v. 11, n. 2, p.167-190, maio/agosto de 2005 


\section{A história de vida do Professor Fredolino Taube}

Fredolino Taube nasceu em $1^{\circ}$ de novembro de 1917, numa região conhecida como Campo dos Quevedos, localizado no município de São Lourenço do Sul, interior do Rio Grande do Sul. Por razões profissionais, ele e sua família foram morar em Pelotas, onde viveu a maior parte de sua adolescência. Cursou o antigo ginásio no colégio Pelotense, onde teve seu primeiro contato com o atletismo, graças a um Professor que lhe foi especial:

“... eu tive um Professor de Educação Física. Muito bom, formidável, onome dele era Roberto Müller... ele foi me incentivando e eu fui fazendo esporte... aprendendo a arremessar disco, peso e dardo [foi] com ele...".

A prática do atletismo levou Fredolino Taube, cada vez mais, a envolver-se com o esporte, passando a disputar com êxito competições de nível estudantil, como ele mesmo nos conta:

"...eu era um pouquinho maior do que todos os outros, um pouquinho mais forte. A gente de Pelotas era tudo meio baixinho (...) eu fui durante todos os 5 anos em que eu fiz lá o ginásio....eu sempre fui campeão, a não ser um não quando eu tava na terceira série do ginásio Apareceu um rio-grandino que veio transferido pro colégio e tirou os primeiros lugares. Me passou na cara em tudo (risos).A gente não pode ser sempre campeão..."

Com os estudos concluídos e sem grandes perspectivas profissionais, Fredolino Taube veio para Porto Alegre, em 1939, com o intuito de cursar Medicina, uma vez que tinha um colega de Pelotas que estava residindo na capital. Esse colega conhecia Dario Tavares, treinador da equipe de atletismo Sport Clube Internacional, para o qual tecera elogios a respeito do atleta e da pessoa Fredolino Taube. Assim, Fredolino foi convidado para competir e morar nas dependências do clube, no Estádio dos Eucaliptos.

Naquela época, existia um curso pré-médico, com duração de três anos e servia como uma seleção prévia aos estudantes de Medicina. Como não se inscrevera neste pré-médico, Fredolino Taube foi procurar emprego e começou a trabalhar como pintor de letreiros. Nessa época, ele já morava em uma pensão e foi aí que encontrou um grupo de professores conhecidos que estavam cursando Educação Física numa Escola que havia sido recentemente fundada: A Escola Superior de Educação Física (ESEF), fundada em 1940. A Medicina ficou de lado, pois, em 1941, ele ingressou na ESEF, formando-se em 1943.

Movimento, Porto Alegre, v. 11, n. 2, p.167-190, maio/agosto de 2005 


\section{A trajetória profissional}

Recém-formado, o Professor Fredolino Taube recebeu duas propostas de emprego do então diretor da ESEF, Capitão da Brigada Militar Olavo Amaro da Silveira: uma delas era para trabalhar no Colégio Júlio de Castilhos e a outra era para ser Professor da própria ESEF. Nosso colaborador aceitou as propostas e só deixaria estes dois empregos ao aposentar-se, em meados da década de 1970, com 35 anos de serviço público.

Fredolino Taube também trabalhou no Instituto Gaelzer, pertencente ao Professor Frederico Gaelzer, que segundo Fredolino Taube, foi um dos precursores da Educação Física no Estado, através das atividades de Recreação Pública. ${ }^{4}$

Além do Instituto Gaelzer, onde trabalhava com fisioterapia, o Professor Fredolino Taube ainda trabalhou no Instituto Santa Luzia, onde lecionava para os deficientes visuais e também na Sociedade Ginástica de Porto Alegre (SOGIPA), como treinador de atletismo:

“... na SOGIPA fui duas ou três vezes técnico. Fui técnico primeiro das moças, depois fui técnico do grupo todo, depois desmembramos de novo deixei de trabaIhar como técnico de atletismo quando eu fui...solicitado para ser coordenador da Escola de Educação Física..."

Como já mencionado, o Professor Fredolino Taube recémformado passou a fazer parte do quadro de professores da Escola. Em face de sua experiência com o atletismo, passou a ser um dos professores da disciplina de atletismo. Coube-lhe ensinar os arremessos e lançamentos:

"Na ESEF eu fui Professor de arremessos... Minha disciplina era lançamentos e o Professor Rubem Emilio, já falecido também... ele era o chefe da disciplina de atletismo...ele dava corridas e saltos e eu ficava com a parte de arremessos"

Para o Professor Fredolino, sua experiência como atleta, treinador e, agora, docente não bastava. Ele sempre buscava se qualificar e aprimorar ainda mais:

“... eu comprava tudo que podia comprar, porque eu não me considerava...um Professor sabido(...) eu sempre tava correndo na frente...tanto é que quando fo.

4 Frederico Guilherme Gaelzer é considerado o introdutor da recreação no Brasil Passou cinco anos nos Estados Unidos (de 1919 a 1924) com o objetivo de buscar o que havia de mais moderno em termos de Educação Física no mundo. o que havia de mais moderno em termos de Educação Física no mundo. O que ele encontrou foi, justamente, um movimento com certas finalidades sociais, denominado "recreação". Foi grande estudioso do assunto, além de organizador

Movimento, Porto Alegre, v. 11, n. 2, p.167-190, maio/agosto de 2005 
inventado o estilo Floop. Não sei se te lembras do estilo Floop em salto em altura? É o de costas...aquilo foi na Alemanha, começaram lá....Eu recebi a revista e com a série de fotos aquelas......com as diferentes fases(...) lá... tinha uns rapazes bons e eu disse: Olha aqui ó... isso aqui nós vamos experimentar aqui na SOGIPA. E mostreicomoé, ensinei comoé..."

Embora especialista em Atletismo, em determinada época houve a necessidade de o Professor Fredolino Taube também lecionar a disciplina de Tênis. Segundo ele, não possuía muita experiência com o esporte Tênis, mas face a necessidade, ele conseguiu contornar esta situação:

"(...) depois entrou tênis... aí foi aquela briga... olharam assim "você vai dar Tênis" Eu não sabia jogar tênis... a toque de caixa peguei um Professor e fui aprender Tênis lá no clube lá em cima em Petrópolis e fui aprendendo (...) o que mais me preocupava era a aquisição de documentos, de livros sobre os assuntos que eu lecionava."

Nosso colaborador ainda teria ministrado a disciplina de levantamento de pesos, segundo um de seus ex-alunos, o hoje também Professor da ESEF Adroaldo Gaya, na década de 1970. Podemos observar que o Professor Fredolino Taube era dedicado ao trabalho e à profissão, sempre preocupado com a qualidade de sua formação. Além disso, podemos observar que como para a maioria dos professores da época, era preciso saber fazer, ou seja, tinha que se praticar determinado desporto para ser um bom professor.

\section{O Professor Fredolino Taube na visão de seus alunos e funcionários}

Segundo os relatos de alguns de seus alunos, Fredolino Taube era um homem de valores éticos e morais bem definidos, que primava pela seriedade e por valorizar questões morais e a responsabilidade das pessoas:

"O que me chama a atenção, principalmente, no Professor Fredolino, era a preocupação com a formação do cidadão, do indivíduo. Ele era e sempre foi um homem de valores muito bem definidos, (...) suas aulas passavam essa preocupação na transmissão de valores, de fraternidade, de valores de seriedade, de valores de... não corrupção (...) sempre situava o Professor como alguém que deveria ser sempre o exemplo, e portanto isto é uma coisa muito importante. Além do que, na sua cultura esportiva, e na época, certamente, um Professor de grandes conhecimentos técnicos naquilo que ensinava e sabia." (Adroaldo Gaya, exaluno.) 
Por outro lado, a seriedade, característica de nosso colaborador, muitas vezes dificultava sua relação com os alunos.

“...uma pessoa que passava assim para os alunos um aspecto demasiadamente sério. Vez por outra até impedia uma maior aproximação. Mas quem como eu tive um momento na monitoria, enecessariamente dele tinha que me aproximar (...) ele foi uma pessoa muito humana e que me deixou valores importantes. Eu acho que sempre tu tens professores que te marcam. (...)o Professor Fredolinoé uma influência que eu considero bastante positiva dentro daquilo que eu acabei sendo como professor.(...)Era... uma pessoa que passava para seus alunos um modelo assim de pessoa com caráter, reto..." (Mário Brauner, ex-aluno)

Numa descrição semelhante à dos alunos, a atualmente aposentada do serviço público Maria do Carmo Giácomo, conhecida pelos ex-alunos e professores como "Tia Carmen", que trabalhou cerca de 25 anos com o Professor Fredolino Taube, acrescenta:

"Sobre responsabilidade nota 10. Daqueles que não tinham horário pra chegare nem pra sair. Orelógio dele não funcionava. Ele dava a vida pela Escola. (...) Ele era uma (pessoa) "reta", muito responsável, sabe (...) as pessoas respeitavam muito, porque ele se fazia por respeitar, tu sabe?

Como já mencionado, um fato muito importante na trajetória do Professor Fredolino Taube era a sua doação à Escola, o que fazia com que, em seu cotidiano na Escola, se realizassem algumas tarefas que iam além de sua função como professor:

"Essa... diríamos hoje que essa... grande honestidade, esta imensa... princípios de valores, chegava assim a raia de uma... ingenuidade. Algumas vezes. ele... tomou posições que talvez hoje não fosse compatíveis com a função que ele tinha, a té como um dirigente da Escola. O Professor Fredolino ia cortar grama no meio do mato. Ele ia pregar alguma janela que estivesse caindo." (Adroaldo Gaya, ex-aluno)

O próprio professor, ao longo das entrevistas, deixou transparecer esse aspecto de sua forma de trabalho ao descrever uma de suas aulas de tênis:

"Era uma cancha de areião e eu muitas vezes dei aulas de tênis...primeiro eu alisava lá com o rastilho. Dava um jeito... para a rapaziada conseguir receber uma aula."

Muito provavelmente foram essas qualidades de seriedade e dedicação que o tornaram diretor da Escola, em 1970.

Movimento, Porto Alegre, v. 11, n. 2, p.167-190, maio/agosto de 2005 


\section{A direção da Escola e a Federalização}

Em 1970, o então diretor da ESEF Hélio Ferreira deixou o cargo de direção que ocupava antes de serem realizadas novas eleições para o cargo de diretor da Escola. Também nesta época, já vigorava o Decreto-Lei 62.997 de 1969, que incluía a ESEF entre as Faculdades e Institutos da UFRGS, e a Escola precisava rapidamente de um novo diretor que cuidasse da Escola naquele importante momento para o seu futuro. Como disse a funcionária aposentada Maria do Carmo: “... alguém tinha que assumir aquilo, pegar a pandorga? Então, o Fredolino que cuidou daquilo lá...".

Foi então que a Secretaria de Educação do Estado, a qual a ESEF estava vinculada, através de um de seus funcionários chamado Professor Sílvio Santos, procurou o Professor Fredolino Taube em uma de suas aulas no Colégio Júlio de Castilhos e o designou para ser o diretor naquele momento de transição.

É importante ressaltar que a Secretária de Educação não teve participação somente nesta questão de sucessão de diretores. Segundo relatos do Professor Taube e da Funcionária aposentada Maria do Carmo, este órgão do Estado mantinha contatos constantes com a ESEF para que esta fosse progressivamente realizando algumas das exigências necessárias para satisfazer o Governo Federal e ser incorporada à UFRGS:

"... eles deviam ter recebido a notificação de que a Escola tinha que satisfazer um montão de quesitos pra poder ser Federalizada. (... .... foi da parte da Secretária da Educação que eu recebi a incumbência de gerenciar a escola, que estava em fase de implantação no sistema federal" (Professor Fredolino Taube).

Entre esses quesitos mencionados pelo professor, Maria do Carmo comenta a necessidade que a ESEF tinha de possuir um patrimônio significativo para que a UFRGS a aceitasse:

“... era pra ser Federalizada em 1969, mas antes disso já tinha uma série de tramitações pedindo a própria doação do terreno, porque implicava muito em a gente ter uma base, ter um pedestal como eu digo para a gente poder chegar lá... porque chegar só com o corpo de funcionários ... não era isso que eles queriam....aí então deu muita força o terreno do Meneghetti... (...) a UFRGS não queria só as pessoas, tinha que ter um bem comum, que eles pudessem ter segurança"

5 Ildo Meneghetti, governador do Rio Grande do Sul que destinou o terreno pertencente ao estado para a construção dos prédios que formavam a ESEF, contribuindo, assim, para a efetivação da Federalização da Escola.

Movimento, Porto Alegre, v. 11, n. 2, p.167-190, maio/agosto de 2005 
O Governo do Estado tinha grande interesse em que a Escola passasse para o Governo Federal, pois, esta pesava muito em seu orçamento. O Governo tinha dificuldades de fornecer à ESEF as condições materiais objetivas necessárias para seu funcionamento. A Escola era um "peso" para o governo estadual.

Para muitos Professores, ser diretor da Escola em tal período poderia ter sido uma experiência ímpar. Contudo, para o Professor Fredolino Taube, não foi algo mais importante do que lecionar:

“... gozado... ser diretor duma entidade... é como eu sempre digo...é um acidente dentro da função de professor... eu sempre digo... a função dele não é isso, a função deleé professor... e eu sempreme considereiprofessor."

Essa preferência de Fredolino Taube pelas atividades de "sala de aula" e pelo contato com os alunos era freqüentemente percebida por aqueles que conviviam com ele:

"Ele sabe... acontece que ele não gostava dessa vida de gabinete (...) ele gostava mais de "trabalhar de verdade". Dar aula: era isso que ele queria.."(Maria do Carmo, ex-funcionária)

Os ex-alunos do Professor Fredolino Taube reforçam esta opinião:

"Chamava a atenção como ele parecia uma pessoa não muito afeita a direção. Não transmitia que era uma coisa que gostava, especialmente nas aulas de atletismo a gente notava ele uma figura saudável e com vontade de passar aquelas coisas que fazia"(Mário Brauner, ex-aluno).

"Pra ele ser diretor não era a coisa mais importante que ser professor. Ele era Professor antes de tudo." (Adroaldo Gaya, ex-aluno).

Entretanto, essa preferência por lecionar não interferiu em seu papel de administrador da Escola. As características pessoais e profissionais de Fredolino Taube fizeram-se presente enquanto Diretor da ESEF:

"... mas eu me empenhei, vamos dizer assim, me empenhei a fundo para que a coisa funcionasse. Esse é o outro aspecto da coisa. A implantação dos departamentos, as reuniões, tudo que concerne a um bom funcionamento de uma escola, dentro de um sistema federal. Eu estava sempre em contato lá com o pessoal da universidade. Então chegava lá, reunia a turma, nomeava os grupos de trabalho e eles se incumbiam do resto, inclusive pesquisando junto às escolas já existentes, para ver o que fazia com que uma escola fosse uma escola do âmbito federal "(Fredolino Taube)

Movimento, Porto Alegre, v. 11, n. 2, p.167-190, maio/agosto de 2005 
A sua passagem pelo cargo ficou caracterizada pela sua forma de ser frente aos alunos e funcionários: um homem sério, discreto, responsável. Um professor que respeitava e fazia-se respeitar. Um profissional que, de fato, "doava-se" para a Escola:

"Por exemplo que eu posso te dizer do trabalho assim...do excelente trabalho de unir o pessoal (...) tínhamos respeito por ele. Já com certos outros diretores a pessoa tem atémais émedo. Ele vinha lá do professorado de atletismo...tá...suado... com o material na mão... ele guardava...e via as coisas erradas e certas também...aí quando ele começou na direção foi outra maneira de ser...outra maneira de conviver com o pessoal..."(Maria do Carmo, ex-funcionária).

"... eu acho que no tempo em que ele foi diretor tinha um pouco da cara dele, porque as coisas funcionavam em termos de horário, funcionavam em termos de que oque tinha estava sendo oferecido(...) parecia que ele era uma pessoa completamente envolvida com aquilo que acreditava. Não tenho receio em dizer quem foi uma pessoa importante em minha formação... a gente sentia que ele estava permanentemente na Escola" (Mário Brauner, ex-aluno).

O que o Decreto-Lei 62.997 havia determinado concretizouse, e uma nova era começaria para a ESEF, agora como Faculdade da UFRGS.

\section{As principais conseqüências do processo de Federalização para a ESEF e para os professores}

No decorrer da década de 1970, a ESEF sofreu muitas modificações em sua estrutura organizacional, na financeira e em seu espaço físico também (criação do LAPEX, por exemplo). Contudo, essas mudanças não aconteceram necessariamente de imediato após a Federalização. Assim sendo, mostraremos as modificações sofridas pela Escola apenas durante a direção do Professor Fredolino Taube, além da repercussão de todos esses fatores na vida do professorado da época.

Em relação à estrutura organizacional, a ESEF, logo que incorporada à UFRGS, teve alguns de seus funcionários dispensados. Isto em razão que antes do Decreto ocorrer, mas já em eminência da Federalização, houve a necessidade de se organizar um quadro com todos os professores e funcionários da Escola, para a futura regulamentação desses como servidores federais. Em relação aos professores, todos ficaram nesse quadro, o mesmo não ocorrendo em relação aos funcionários, segundo a colaboradora Maria Do Carmo.

Movimento, Porto Alegre, v. 11, n. 2, p.167-190, maio/agosto de 2005 
Nosso colaborador explica o acontecido:

"Quando entrou na Universidade eu recebi um papel da reitoria assinado pelo reitor de que todos aqueles funcionários e professores que não eram nomeados dentro da Escola tinham que ser dispensados... .aíme caiu esta bomba na mão"

O fato de que alguns funcionários não permaneceram na Escola deveu-se a duas questões: uma que a Universidade realmente tinha interesse que a Escola reduzisse seu número de funcionários com o intuito de reduzir a folha de pagamento. A outra razão foi que muitos dos que saíram o fizeram porque estavam desgostosos com o nível de salário da ESEF enquanto estadual, que não era muito alto.

Em relação às finanças, também foi significativa a mudança de recursos disponíveis para a Escola se compararmos a ESEF de antes com a de pós-Federalização. A exemplo da remuneração, que segundo relatos não era muito alta, o dinheiro para a aquisição de recursos materiais oriundo do governo estadual deixava a desejar. Muitas vezes, os próprios funcionários tinham que juntar um pouco de dinheiro de cada um para comprar equipamentos e utensílios básicos para o funcionamento da Escola.

“(...) as verbas naquela época eram mínimas. No tempo que eu tava lá eu me lembro que às vezes tinha que comprar material e era uma briga"(Fredolino Taube)

“(...) em 1963,64,65,66,67,68,69éramos mantidos pelo estado, assim mantidos numa maneira de dizer, porque eles não davam nada pra nós. Precisava duma vassoura tinha que dar um jeito e comprar. Precisava duma tinta tinha que comprar(...) então tu vendia um polígrafo e aí aquilo ajudava a comprar mais um material"(Maria do Carmo, ex-funcionária)

Contudo, depois da Federalização, felizmente para a ESEF essa rotina de recursos limitadíssimos deixou de ser uma constante. A Universidade possuía um depósito de materiais e cada Faculdade da Universidade possuía requisições para solicitar o material que precisasse:

“... eu podia gastar X valor, eu fui lá e comprei umas coisas que eles nem pensavam em ter: Vassoura de cabelo, vassoura pro chão, para a laje (...) e era escova, era sabão, era os detergentes, e tudo em quantia (...) e eu tinha gastado só uma parte do orçamento, não tinha gastado todo, é claro aquilo tudo deu vida pra escola, sabe? Então a gente começou a viver uma vida diferente na Escola (...) a gente não tinha nada!" (Maria do Carmo, ex-funcionária)

O fato de ser uma Faculdade Federal produziu muitas modificações na estrutura física da ESEF. A Escola, poucos anos

Movimento, Porto Alegre, v. 11, n. 2, p.167-190, maio/agosto de 2005 
depois de ser incorporada à Universidade, passou a receber reformas em sua velha estrutura e também a ganhar novas edificações:

"... a nossa cancha de tênis era uma porcaria de cancha lá...agora ..aterraram tudo aquilo lá, fizeram canchas de cimento (...) depois da Federalização (...) aí veio verba, fizeram uma boa piscina, aquecida, e construíram um estádio, botaram Tartan na pista, aquela cobertura, tudo isso não existia. Tudo depois da entrada pro governo federal. A mudança para o federal foi muito boa porque em poucos anos a Escola floresceu, ela ficou outra coisa..." (Fredolino Taube).

Até a Federalização, a ESEF centrava todas as suas aulas em sua Unidade. Entretanto, teve que se adaptar a estrutura de departamentos que começou a vigorar na Universidade logo após a Reforma Universitária. Assim, disciplinas, por exemplo a de anatomia, saíram do ESEF para serem ministradas no Campuscentro da UFRGS:

"A princípio foi meio confuso, sabe? Porque nós tivemos que terminar com aquelas turmas que comecaram seriadas, para que os novos que entrassem já entrassem dentro do novo regime de disciplinas. (...) fazer anatomia na sala de anatomia da Faculdade de Medicina e outros em outros lugares, Faculdade de Educação, e aquilo não existia antes, o aluno estava dentro e não perdia tempo em deslocamento."(Fredolino Taube)

Também como conseqüência da adaptação à estrutura organizacional da UFRGS, a ESEF passou a adotar o sistema de Créditos. A ESEF anterior à Federalização tinha uma estrutura semelhante à do atual ensino Médio. Esse quadro modificou-se com a Federalização: o sistema seriado foi substituído pelo de créditos, o que exigiu um período de adaptação de professores e alunos:

"Antes então era uma coisa mais palpável pro aluno. Ele sabia que estava na segunda série e tinha mais um ano pela frente. Quando passamos para o sistema de disciplinas, aí a coisa ficou meio difícil. Parece-me que não só os alunos, mas os próprios professores se sentiram meio perdidos dentro daquele sistema, porque nós não estávamos acostumados com aquilo. "Mas e a disciplina tal não seria do último ano de...?" (Risos) "... e faz agora antes???" Então tivemos que fazer um trabalho no sentido de fazer uma ordenação nas disciplinas. Foi um trabalho bastante difícil. Então nós tínhamos reuniões para a implantação dos departamento. No fim tudo certo, tudo funcionou."

Além do exposto acima, para o Professor Fredolino Taube essas modificacões foram determinantes para que os alunos "perdessem sua identidade de turma". Embora ele reconheça que a matrícula por disciplinas facilitasse para o aluno a realização da 
Faculdade, também fez com que as turmas se dispersassem ao longo do curso:

“...começou com onegócio das disciplinas. O cara faz lá a disciplina e se desvincula do resto. Ele não faz parte da escola, ele faz aquela disciplina. Quando o cara tirava uma série, ele fazia parte da escola, não é?(...) A disciplina foi feita para facilitar o estudo dos alunos. O cara não tem tempo pra fazer a série, daí a disciplina. Se ele tem tempo, ele faz tudo.(...) E com isto ele (o processo de Federalização) desmanchou aquilo que era antigamente série e tal. Então às vezes eu ficava chateado por causa disso."(Fredolino Taube)

Ainda em conseqüência da Federalização, o ingresso da ESEF passou a ser através do concurso vestibular, a exemplo das demais Faculdades da UFRGS. Além disso, a ESEF, que até então centrava suas aulas no período da manhã, passou a ter atividades à tarde:

"Depois da Federalização passou-se a ter o vestibular junto com os outros (...) de início preenchiam as vagas os últimos classificados, e aquilo desagradou a mai oria dos professores, porque aqueles não tinham vocação para Educação Física. nós então ficamos ainda alguns tempos fazendo provas práticas, que também caíram. Chegaram a conclusão que durante o curso há uma seleção natural." (FredolinoTaube)

“... nós também começamos a colaborar com eles na matrícula, bem diferente do nosso sistema, porque lá a gente fazia tudo rápido, no balcão. Com eles são formulários, fichas e tudo(...) aí começaram em 71 ou 72 a ter aulas na tarde, que não tinha..."(Maria do Carmo, ex-funcionária)

Essas foram as principais conseqüências da Federalização para a Escola de Educação Física, pelo menos no curto prazo. Diferentedo que aconteceu para a instituição, a Federalização não resultou em maiores alterações na vida dos professores da época. Do ponto de vista financeiro, por exemplo, o salário de Professor não se elevou significativamente com a condição de Professor de Universidade Federal:

"...todos achamos que foi um bom negócio entrar na universidade, mas monetariamente não se melhorou... pouca coisa..."(Fredolino Taube)

Contudo, outros aspectos devem ser analisados. Por exemplo, quando entrevistamos os ex-alunos da época da Federalização sobre o processo (NUNES et all., 2000), eles foram unânimes ao afirmar que se sentiram valorizados com o fato de serem estudantes de uma organização como a UFRGS. Ou seja, uma questão de status. Questionado sobre essa possibilidade, Fredolino Taube nos disse:

Movimento, Porto Alegre, v. 11, n. 2, p.167-190, maio/agosto de 2005 
“... não achei nada de interessante, eu não faria...eu nunca fiz alarde disto, sabe, mas em geral o cara usava esta coisa. O cara dentro da Universidade "Ah! Eu sou Professor universitário!" Eu sou assim, não faço questão. Eu queria era trabalhar sabe."

Embora o Professor Fredolino Taube não se importasse com isso, podemos observar que a questão do status não se limitava apenas aos alunos.

\section{Considerações transitórias}

Pelo exposto até o momento, podemos observar que se a Federalização modificou de maneira significativa a estrutura da ESEF, o mesmo não podemos falar acerca do impacto sobre os Professores do período. Entretanto, entendemos que este é o ponto de vista de um dos professores do período, que mesmo sendo uma pessoa em destaque no processo, pode não refletir todo o significado da Federalização para todo o corpo docente. Ainda assim, pensamos que algumas alterações devem ter ocorrido.

Sabemos que a Escola antes da Federalização possuía aulas somente no turno da manhã. Contudo, após o processo, esta passou a ter aulas no turno da tarde. Sabemos que o Professor Fredolino Taube era também Professor do Colégio Júlio de Castilho e também treinador da SOGIPA. Na época, trabalhar em outros lugares era comum entre os professores da ESEF. E após a Federalização? Provavelmente alguns professores tiveram que reorganizar seus compromissos profissionais, ou até mesmo renunciar a algum de seus empregos. Se algo semelhante aconteceu, temos então mais um significativo efeito na vida dos professores do período.

Outra questão pertinente vem da departamentalização. Essa transformação acarretou alterações organizacionais na ESEF, como o fato de as aulas de anatomia passarem a ser ministradas na Faculdade de Medicina. Dessa forma, os professores das disciplinas na ESEF tiveram que se adaptar a uma nova forma de organização institucional, a interagir com outros colegas, alterar as questões de rotina da instituição, pois, agora, pertenciam a um departamento da UFRGS. O mesmo pode ter ocorrido com os professores ligados a disciplinas de outros Departamentos da Universidade que vieram a ministrar disciplinas na ESEF, ou então a receber alunos de Educação Física em suas turmas. De-

Movimento, Porto Alegre, v. 11, n. 2, p.167-190, maio/agosto de 2005 
vido às circunstâncias e à proposta de nossa investigação, não podemos afirmar como isso aconteceu na prática. Reconhecemos que relatos de outros professores que vivenciaram tais fatos seriam importantes para compreender melhor a Federalização.

É importante ressaltar a ausência de observações do Professor Fredolino sobre a política da época. Ficou evidente, ao longo da pesquisa, que ele não era muito afeito às questões administrativas da ESEF, preferindo visivelmente "ser Professor". Da mesma forma, quando abordávamos a questão da ditadura militar, o Professor pouco falava a respeito. A funcionaria Maria do Carmo nos respondeu da seguinte forma sobre o interesse do Professor Fredolino Taube em relação à política e afins:

“...essa parte ele não gostava. Ele cortava, de levemente cortava. Ele era muito delicado para tratar com as pessoas, sempre foi, mas ele era apolítico. Não se sabia se ele era a favor dum governo ou contra" (Maria do Carmo, ex-funcionaria)

Se considerarmos todo o contexto político-ideológico e a política educacional do momento, já expostos ao longo do texto, é coerente admitir que entre os atributos do Professor Fredolino Taube - um cidadão responsável e honesto; um Professor e treinador com conhecimento técnico e larga experiência em sua área de atuação - deva-se somar mais esse: um professor que permanecia numa posição política neutra, ou ao menos que não se manifestava publicamente. Inferimos que isto teve influência no momento de sua escolha para administrar a Escola, uma vez que se o futuro Diretor tivesse uma posição crítica ao governo, além do risco de ser "censurado", poderia comprometer todo o processo de Federalização.

Se não ficaram esclarecidas as convicções políticas do Professor Fredolino Taube, ficou evidenciado que esse professor se caracterizava como um homem humilde, íntegro e dedicado; um professor que respeitava e se fazia respeitar tanto em questões acadêmicas quanto em questões cotidianas; uma pessoa que evitava intrigas, discreto, a exemplo de outros professores dessa instituição, que muito somaram para que a ESEF se transformasse na ESEF da UFRGS e se tornasse uma referência entre as Escolas de Educação Física brasileiras.

Movimento, Porto Alegre, v. 11, n. 2, p.167-190, maio/agosto de 2005 


Federalization process of the School of Physical
Education of the Federal University of Rio Grande Sul
from the perspective of its professors: a case study
Abstract: The present research is a case study that aims
to understand, from the professors' perspective, the
process of incorporation of the School of Physical
Education to the Federal University of Rio Grande do Sul,
Brazil, which occurred in 1969. The analytical process
tries to relate the sociopolitical context at that time with
the history of life of a professor then in activity.
Keywords: School of Physical Education; Incorporation;
Case Study.

El proceso de federalización de la Escuela de Educación
Física de la Universidad Federal de Rio Grande do Sul
bajo la perspectiva de los profesores: un estudio de
caso
Resumen: Esta investigación es un estudio de caso que
tiene por objetivo comprender el proceso de incorporación
de la Escuela Superior de Educación Física a la Universidad
Federal de Rio Grande do Sul, que ha ocurrido en 1969,
en la perspectiva de los profesores. El proceso de análisis
relaciona el contexto sociopolítico de la época con la
historia de vida de un profesor de esa época.
Palabras-clave: Escuela Superior de Educación Físi-
ca; incorporación; Estudio de Caso.

\section{Referências}

BARROS, E. L. Os Governos Militares. São Paulo: Contexto, 1994.

BARROS, E. L. O Brasil de 1945 a 1964. São Paulo: Contexto, 1994

CASTELLANI FILHO, L. Educação Física no Brasil: a história que não se conta. Campinas, São Paulo: Papirus, 1988.

DAMASCENO, R. N. A Reforma Universitária e o seu caráter ideológico. Educação, Porto Alegre, V. 1, p. 87-97: PUCRS, 1978.

LAMPERT, E. A Reforma Universitária: o caos no ensino superior. Momento, Rio Grande, V. 8, p. 163-167: Editora da FURG, 1995.

Movimento, Porto Alegre, v. 11, n. 2, p.167-190, maio/agosto de 2005 
NUNES, C. F. T. et al.. O Processo de Federalização da Escola de Educação Física: a visão dos alunos formandos em 1968, 1969 e 1970. Salão de Iniciação Científica. Porto Alegre: UFRGS, 2000.

NUNES, C. F. T. E MOLINA NETO, V. O processo de Federalização da Escola de Educação Física na perspectiva dos professores. Salão de Iniciação Científica. Porto Alegre, 2002.

ROMANELLI, O. O. História da Educação no Brasil. (6a ed.). Petrópolis, RJ: Vozes. 1978

SOUZA, E. S. Meninos á marcha! Meninas à sombra! História do ensino da Educação Física em Belo Horizonte. Belo Horizonte: UFMG, 1995.

TRIVIÑOS, A. N. S. Introdução à pesquisa em ciências sociais: a pesquisa qualitativa em educação. São Paulo: Atlas, 1987.

TAMIOSSO, Míriam Margarete Silva; MAZO, Janice Zaperllon. Uma abordagem histórico-crítica da Educação Física na década de 60. Kinesis, número 7, 41-61, 1991;

UFRGS. Ata do Conselho Universitário. Reunião $n .^{\circ} 373$ de fevereiro de 1968, Porto Alegre: CONSUN/UFRGS, 1968.

XAVIER, Maria Elisabete et al. História da Educação: a escola no Brasil. São Paulo: FTD, 1994. 